\title{
Collective information storage in multiple synapses enables fast learning and slow forgetting
}

\author{
Michael J Fauth ${ }^{1 *}$, Florentin Wörgötter ${ }^{1}$, Christian Tetzlaff2,3 \\ From 24th Annual Computational Neuroscience Meeting: CNS*2015 \\ Prague, Czech Republic. 18-23 July 2015
}

Most of the excitatory cortical synapses reside on dendritic spines. Although these spines undergo a remarkably high turnover $[1,2]$, they have been shown to be involved in learning and long-term memory. Along this line, it is unclear how information is preserved while its substrate (synapses or spines) is permanently changing.

Here, we use a simple stochastic model of structural plasticity to investigate this phenomenon : We assume a certain number of potential synaptic locations from one neuron to another.

At those locations, synapses (spines) are created with a constant probability and removed with a probability depending on the number of existing synapses and the stimulation of the neurons. From these two probabilities, the stationary distribution of the number of synapses between two neurons can be calculated.

Experimental measurements of these stationary probability distributions in the cortex show that the majority of connections has either zero or multiple synapses while one or two contacts are very improbable [e.g., [3-5]]. Using information theoretic measures we show that, in our model, such bimodal distributions enable information storage over time scales many orders of magnitudes higher than the involved probabilities. Thus, in this system the conflict of rapid spine turnover (probabilities) and long-term memory is resolved by storing the information collaboratively in multiple synapses.

In the following, we will consider the bimodal stationary distributions as the working point of the system. Then, we can model external signals, as, e.g., increased or decreased activities during learning, as changes of the removal probabilities and stationary distributions (e.g., mediated by synaptic plasticity [6]).

\footnotetext{
* Correspondence: mfauth@gwdg.de

${ }^{1}$ Bernstein Center for Computaional Neuroscience, Third Physics Institute, Göttingen, Germany

Full list of author information is available at the end of the article
}

For instance, for learning signals resulting to unimodal stationary distributions (only connected or only unconnected), we find that learning is orders of magnitude faster than forgetting. Along this line, we observe that retraining a task does not induce an increased overturn rate as during initial training, which has been similarly observed for dendritic spines in vivo [1,2]. Our results clearly relate the difference in time scales to the shape of the stationary distribution and therefore reveal the functional advantage of the bimodal distribution found in experiment.

\section{Authors' details}

${ }^{1}$ Bernstein Center for Computaional Neuroscience, Third Physics Institute, Göttingen, Germany. ${ }^{2}$ Max Planck Institute for Dynamics and SelfOrganization, Göttingen, Germany. ${ }^{3}$ Weizman Institute, Rehovot, Israel.

Published: 18 December 2015

\section{References}

1. Yang G, Pan F, Gan WB: Stably maintained dendritic spines are associated with lifelong memories. Nature 2009, 462:920-924

2. Xu T, Yu X, Perlik AJ, Tobin WF, Zweig JA, Tennant K, et al: Rapid formation and selective stabilization of synapses for enduring motor memories. Nature 2009, 462:915-919.

3. Feldmeyer D, Egger V, Lübke J, Sakmann B: Reliable synaptic connections between pairs of excitatory layer 4 neurones within a single 'barrel' of developing rat somatosensory cortex. J Physiol 1999, 521(1):169-190.

4. Feldmeyer D, Lübke J, Silver RA, Sakmann B: Synaptic connections between layer 4 spiny neurone-layer $2 / 3$ pyramidal cell pairs in juvenile rat barrel cortex: physiology and anatomy of interlaminar signalling within a cortical column. J Physiol 2002, 538(Pt 3):803-822.

5. Hardingham NR, Hardingham GE, Fox KD, Jack JJB: Presynaptic efficacy directs normalization of synaptic strength in layer 2/3 rat neocortex after paired activity. J Neurophysiol 2007, 97(4):2965-2975.

6. Fauth $M$, Wörgötter $F$, Tetzlaff $C$ : The formation of multi-synaptic connections by the interaction of synaptic and structural plasticity and their functional consequences. PLOS Comput Biol 2015, 11(1):e1004031.

doi:10.1186/1471-2202-16-S1-015

Cite this article as: Fauth et al:: Collective information storage in multiple synapses enables fast learning and slow forgetting. $B M C$ Neuroscience 2015 16(Suppl 1):O15.
() Biomed Central

C 2015 Fauth et al. This is an Open Access article distributed under the terms of the Creative Commons Attribution License (http:// creativecommons.org/licenses/by/4.0), which permits unrestricted use, distribution, and reproduction in any medium, provided the original work is properly cited. The Creative Commons Public Domain Dedication waiver (http://creativecommons.org/publicdomain/ zero/1.0/) applies to the data made available in this article, unless otherwise stated. 